\title{
ANALISIS DESAIN LANGIT- LANGIT ISTANA MAIMUN
}

\author{
ANALYSIS OF MAIMUN PALACE SKY DESIGNS
}

\author{
Noprita Elisabeth Sianturi
}

Fakultas Seni dan Desain

Universitas Potensi Utama

Jl. K.L. Yos Sudarso Km 6,5 No. 3A Tanjung Mulia Medan Sumatera Utara 20241 Indonesia noprita_elisabeth@potensi-utama.ac.id

\begin{abstract}
Abstrak
Tujuan penelitian ini adalah untuk menganalisa bentuk atau motif dari langit-langit atau plafon, atau bagian dari Istana Maimun yang memuat unsur budaya dari mana saja, sehingga masyarakat dapat mengetahui unsur (budaya) yang terkandung dari pembangunan Istana MaimunIstana Maimun adalah sebuah bangunan sejarah peninggalan bagi umat Melayu yang didirikan oleh Kesultanan Deli dengan ciri khas warna kuning sebagai dasar pembangunannya, Istana Maimun merupakan sebuah tujuan wisata yang ada dikota Medan, bangunan Istana Maimun merupakan bangunan yang dibuat oleh seorang arsitek dari negara Belanda, istana tersebut dibangun dengan memadukan berbagai unsur budaya dari berbagai negara seperti India, Spanyol, Persia, Italia, Eropa dan Timur Tengah. Hasil dari pengematan dan penelitian bahwa motif langitlangit Istana Maimun mengandung banyak campuran relief dari Timur Tengah dan Persia serta Kebudayaan Melayu, serta warna langit-langit Istana Maimun bercirikan warna kuning, dimana warna kuning melambangkan kebudayaan Melayu.
\end{abstract}

Kata Kunci : istana Maimun, langit-langit, budaya, Melayu

\begin{abstract}
The purpose of this study is to analyze the shape or motif of the ceiling or ceiling, or part of Maimun Palace which contains cultural elements from anywhere, so that people can know the elements contained in the construction of Maimun Palace Istana Maimun is a historical heritage building for Malay people founded by the Deli Sultanate with distinctive yellow characteristics as the basis for its development, Maimun Palace is a tourist destination in the city of Medan, the building of Maimun Palace is a building created by an architect from the Netherlands, the palace was built by combining various cultural elements from various countries such as India, Spain, Persia, Italy, Europe and the Middle East. The results of the conservation and research that the ceiling motif of Maimun Palace contains a great mix of reliefs from the Middle East and Persia and Malay Culture, and the color of the ceiling of the Maimun Palace is characterized by yellow, where the yellow symbolizes Malay culture.
\end{abstract}

Keywords : Maimun palace, ceiling, culture, Melayu

\section{PENDAHULUAN}

Istana Maimun adalah sebuah istana Kesultanan Deli, istana ini dibangun dahulu untuk tempat peristirahatan sultan pada waktu itu, Istana ini pembangunannya waktu masa pemerintahan Sultan Makmun Al Rasyid Perkasa Alamsyah, anak pertama dari Sultan Mahmud Perkasa Alam tahun 1888 . 
Ada beberapa warisan budaya yang berada di Indonesia terutama di kota Medan, dan salah satunya adalah Istana Maimun. Istana Maimun ini sekarang berada di tengah-tengah kota Medan dan salah ikon kota Medan selain dari Mesjid Raya, Rumah Jong A Fie, Istana Maimun juga sebagai salah satu tujuan wisata yang sering dikunjungi oleh wisatawan domestik maupun mancanegara.

Istana Maimun merupakan istana yang sebuah icon kebanggaan masyarakat kota Medan, istana tersebut adalah peninggalan orang Melayu bahwa pada zaman dahulu sampai saat ini masih tetap ada kerajaan Tanah Deli tersebut.

Penelitian ini bertujuan untuk meningkatkan pengetahuan atau memberitahukan tentang sejarah istana Maimun sekaligus makna dari bangunan yang ada didalam istana Maimun tersebut.

\section{STUDI LITERATUR}

Berdasarkan informasi dan data yang sudah didapat, maka proses dan tahapan menganalisis desain langit-langit istana Maimun ini dapat ditangkap dengan mudah dan dapat dicerna dengan baik dan sistematis maka ada beberapa urutan-urutan penyelesaian yaitu penyusunan metode, strategi, perancangan yang terstruktur.

\section{A. Metode Perancangan}

Untuk mendapatkan hasil yang maksimal dari menganalisis desain langit-langit istana Maimun ini secara efesien dan efektif, serta maksud dan tujuan yang diinginkan tercapai, maka ada langkah-langkah yang dilakukan.

\section{B. Ruang Lingkup Perancangan}

Agar dalam menganalisis desain langit-langit istana Maimun ini mendapatkan hasil yang maksimal sehingga tercapai maksud yang diinginkan, untuk itu dibuatlah ruang lingkup dalam menganalisis desain langit-langit istana Maimun. Target yang ingin dicapai dalam menganalisis desain langit-langit istana Maimun adalah semua orang atau masyarakat luas dengan target sebagai berikut :

\section{Demografis \\ Usia : anak-anak, remaja, orang tua \\ Jenis kelamin : laki-laki dan perempuan}

\section{Geografis}

Lokasi tempat penelitian dilakukan adalah di Kota Medan.

\section{Pisikografi}

Targetnya untuk analisis desain langit-langit Istana Maimun adalah semua kalangan masyarakat tanpa terbatas usia dan tempat.

\section{Metode Pengumpulan Data \\ 1. Data verbal}

a) Wawancara

Wawancara yang dilakukan untuk mendapatkan data-data yang diinginkan adalah dengan tatap muka atau berbicara dengan beberapa nara sumber termasuk orang-orang yang mengetahui tentang latar belakang istana Maimun dan juga bertemu dengan orang yang tinggal dilingkungan istana Maimun.

b) Observasi

Observasi juga harus dilakukan untuk mendapatkan data yang akurat dengan mengunjungi secara langsung ke Istana Maimun untuk mengetahui lebih dalam apa saja yang ada di istana Maimun sekaligus mengetahui makna yang terkandung setiap bangunan istana Maimun.

\section{Landasan Teori}




\section{Pengertian Estetika}

Secara etimologis, istilah "estetika" berasal dari kata sifat dalam bahasa Yunani, aisthetikos, yang artinya 'berkenaan dengan persepsi'. Bentuk kata bendanya adalah aisthesis, yang artinya 'persepsi indrawi'. Sementara bentuk kata kerja orang pertamanya adalah aisthanomai, yakni 'saya mempersepsi'. Pengertian 'indrawi' di sini sangant luas, menncakup penglihatan, pendengaran, sekaligus juga perasaan. Dalam konteks Yunaninya, istilah itu lazimnya dibedakan dari noesis, yakni 'persepsi konseptual 'atau 'pikiran' (Tatarkiewicz 1980:311)

Estetika, sebagai filsafat seni, merupakan pendekatan atas kesenian yang mengabstraksikan aspek-aspek partikular karya untuk sampai pada kesimpulan tentang masalah-masalah universal dalam kesenian. Pada aras filsafat, cabang itu antara lain adalah sebagai berikut :

- Ontologi : kajian filosofis tentang hakikat kenyataan.

- Epistemologi : kajian filosofis tentang asal-usul pengetahuan dan asas -asasnya.

- Filsafat sosial : kajian filosofis tentang asas-asas yang bekerja dalam masyarakat.

Demikian pula halnya dengan estetika. Ketiga cabang itu adalah sebagai berikut :

- Ontologi seni $\quad$ : kajian filosofis tentang hakikat karya seni.

- Epistemologi seni : kajian filosofis tentang proses pengetahuan yang melatari penciptaan karya seni dan pemahaman atas karya seni.

- Filsafat sosial seni : kajian filosofis tentang hubungan antara kesenian dan masyarakat (termasuk estika dan politik).

\section{Manfaat Estetika}

Dalam konteks seni rupa Indonesia, perdebatan estetis macam itu sudah berlangsung setidakya sejak munculnya perlawanan para perupa dalam kelompok Persatuan Ahli Gambar Indonesia ( Persagi ) terhadap para perupa "Hindia Elok" (Mooi Indie) (Sudjojono 2012: 21-24). Masalah-masalah estetika itu masih terus diperdebatkan di masa kini. Kedatangan new media, misalnya, seperti mengungkit perdebatan estetis lama tentang kriteria yang sahih dalam membedakan karya seni dan bukan karya seni . Tak pelak lagi, masalah-masalah fundamental estetika akan terus kita perdebatkan selama sejarah seni masih bergulir.

\section{Metode Estetika}

Sebagai ilustrasi awal, perbedaan antara metode sejarawan seni, kurator, dan estetikawan dapat dipotret dalam jenis- jenis pertanyaan berikut :

- Pertanyaan Sejarawan seni :

- “Apakah Beethoven seorang komponis Klasik atau Romantika?"

- Pertanyaan kurator :

- “Apa makna karya instalasi ranjang Trayek Emin?”

- Pertanyaan estetikawan :

- “Apa yang membuat suatu karya indah menjadi indah? Apakah boks Brillo yang dipamerkan Warhol sama indahnya dengan boks yang sama yang baru selesai diproduksi di pabrik?" 


\section{Istana}

Istana merupakan sebuah bangunan yang mewah dan tentunya besar dan biasanya digunakan untuk peristirahatan keluarga besar kerajaan atau raja, atau bisa juga untuk seorang kepala negara dan sebagainya. Makna dari kata istana biasanya juga digunakan untuk menyebutkan sebuah bangunan yang digunakan sebuah lembaga atau perusahaan. Seperti di daerah Jawa, istana biasanya digunakan sebagai tempat tinggal para raja atau keluarga raja.

\section{PEMBAHASAN}

Istana Maimun dilaksanakan pembangunannya waktu Sultan Makmun Al Rasyid Perkasa Alamsyah berkuasa atau naik tahta, Sultan Makmun Al Rasyid adalah anak pertama dari Sultan Mahmud Perkasa Alam.

Sultan Makmun Al Rasyid naik tahta sebagai pengganti Sultan Mahmud Perkasa Alam sebagai Raja Kesultanan Deli dimulai pada tahun 1873 sampai 1924, Sultan Makmun Al Rasyid bergelar sebagai Sultan Deli yang ke-IX. Pada bangunan istana Maimun didominasi warna kuning dan terlihat sangat menonjol sekali di bangunan bagian luar dan bagian dalam Istana tersebut dikarenakan warna kuning adalah ciri khas Kesultanan dan kebudayaan Melayu.

Istana dibangun dimulai dari tanggal 26 Agustus 1888, setelah selesai langsung diresmikan tanggal 18 Mei 1891. Istana Maimun dibangun diatas tanah seluas $2.772 \mathrm{~m}^{2}$, terdiri atas tiga bangunan utama yang berisi 30 kamar. Bangunan induk disebut juga Balairung dengan luas $412 \mathrm{~m} 2$, dimana singgasana kerajaan berada istana maimun ini diarsiteki oleh seorang arsitek Belanda yang bernama TH Van Erp, dimana pembangunan istana tersebut menggabungkan beberapa budaya Melayu, Islam, Spanyol, India, dan Italia.

Langgam arsitektur pada istana maimin ini perpaduan dari beberapa arsitektur beberapa negara. Selain dari khas melayu terdapat juga beberapa langgam khas budaya lainnya seperti islam, india, spanyol, dan italia. Dominasi warna kuning pada seluruh Istana Maimun melambangkan kebesaran bangsa Melayu. Sementara, nuansa Persia tampak dari tiga kubah yang menaungi bagian depan istana ini. Bentuknya melengkung bagaikan perahu terbalik.Selain itu, gerbang utama Istana Maimun juga menandakan unsur budaya India. Adapun pengaruh Andalusia terlihat pada bagian depan dan interior Istana Maimun. Pilar-pilar bangunan ini menyerupai yang terdapat di Masjid Kordoba.Demikian pula dengan corak geometris, langit-langit interior, dan penempatan koridorkoridor di dalam istana tersebut. Persentuhan budaya modern tampak dari perabotan yang ada, semisal kursi, meja, lemari, lampu-lampu gantung, atau pintupintu ruangan. Di beberapa titik terdapat inskripsi yang memuat keterangan dalam bahasa Belanda aksara Latin.

Desain Eropa Barat terlihat antara lain dari ukiran kepala singa di sejumlah perabotan utama. Selain itu, di ruangan utama terdapat singgasana yang seluruhnya berwarna kuning, menyimbolkan kemegahan kesultanan Melayu.

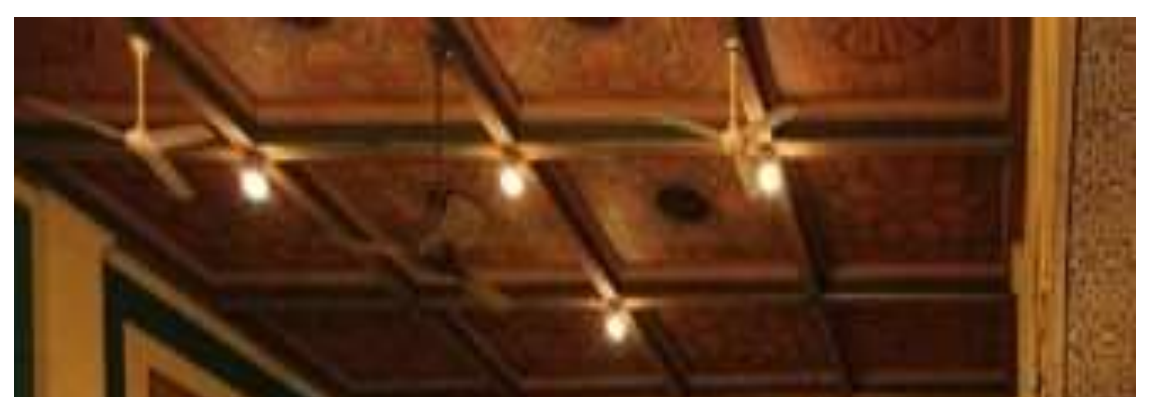




\section{Gambar 1. Langit-langit istana Maimun}

Arsitekturnya dengan warna kuning sebagai warna khas kebudayaan melayu masih terlihat baik. Dimana bangunannya dengan pola memanjang dan terdiri bertingkat dua serta terdapat ukiranukiran khas budaya melayu masih terlihat dengan jelas pada interior bangunan dan langit-langit istana juga berbentuk pucuk rebung. Dan pada dinding bangunan istana terdapat motif awan boyan yang merupakan ciri khas kebudayaan melayu.

Pola langit-langit istana maimun mengandung ciri pola kubisme dimana pola tersebut merupakan percampuran dari arsitektur langgam india moghul. Serta terdapat juga pola arsitektur dari arab (islam) pada setiap tiang bangunan istana maimun terdapat bentuk arcade setengah lingkaran. Kubah istana maimun yang berada di depan mengadopsi bentuk langgam arsitektur islam.

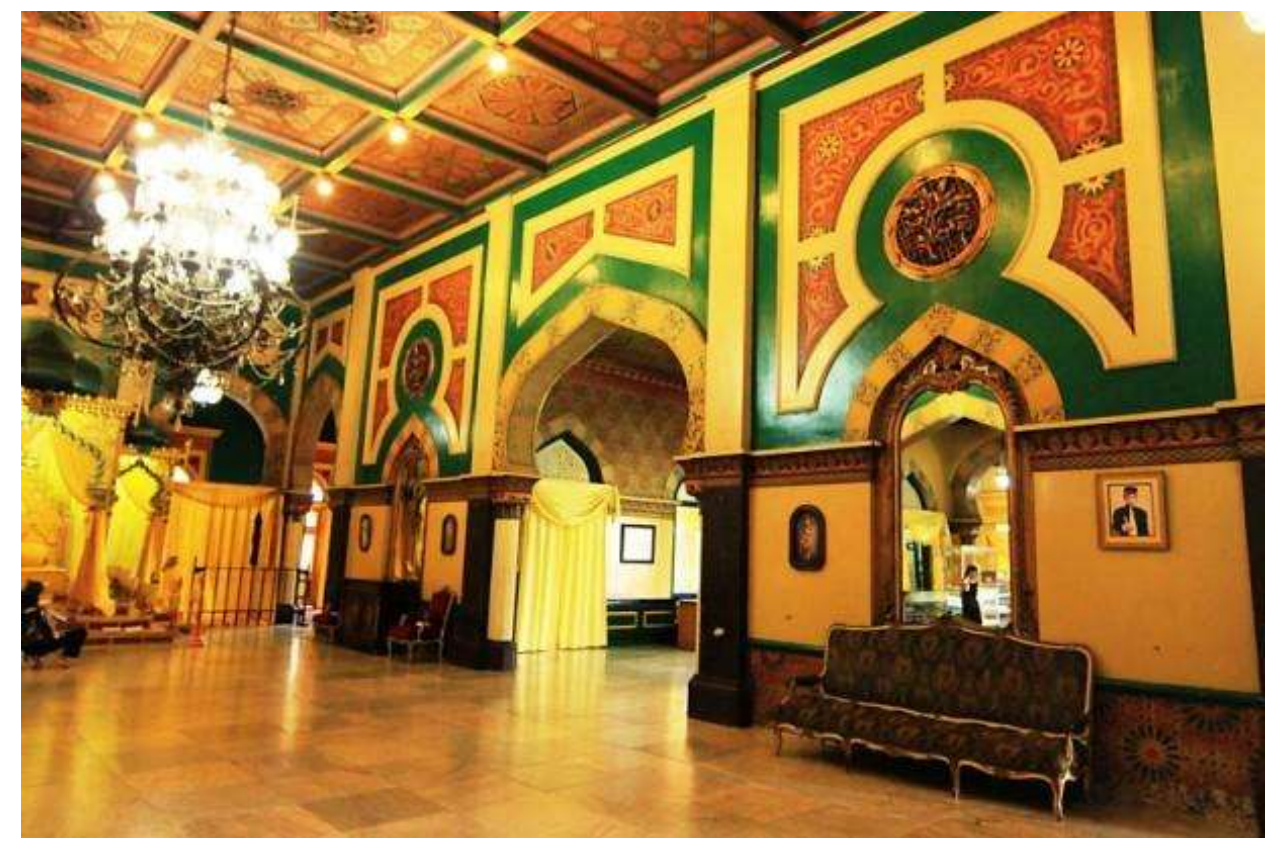

Gambar 2. Ruangan bagian dalam Istana Maimun

Selurun bangunan Istana Maimun mempunyai luas lebih kurang $2772 \mathrm{~m} 2$, serta dari denah yang ada bahwa seluruhnya dibagi menjadi tiga bagian, yakni terdiri dari bangunan induk, sayap kiri dan kanan. Bangunan induknya mempunyai panjang bangunan dari depan dan kebelakang sekitar 
75,30 m serta tingginya 14,40 m. Atap bangunan istana maimun mempunyai bentuk limasan dan kubah, dan bahannya dibuat dari atap sirap dan tembaga (seng). Dilihat dari sudut arsitektur secara keseluruhan bentuk atap istana maimun terdiri dari bangunan bertingkat dua. Apabila kita melihat melalui koridor bertangga yang terbuat dari batu pualam, dan dapat naik langsung ke tingkat dua dari bangunan induk yang berteras di kiri dan kanannya yang disebut anjungan. Tempat duduk Sultan yang berfungsi untuk menerima tamu-tamu resmi dimana pintunya mengandung konsep ala Eropa. Melalui gerbang dengan lengkungan yang berbentuk lunas perahu terbalik yang penuh dengan ukiran-ukiran motif floralistis dan geometris kita memasuki ruangan induk pada bangunan induk seluas $412 \mathrm{~m} 2$ yang dahulu berfungsi sebagai balairung. Ruangan ini biasa dipakai sebagai tempat upacara penobatan raja dan upacara adat lainnya dan juga sebagai tempat untuk menerima tamu pembesar kesultanan lainnya. Balairung dihiasi dengan lampu-lampu kristal yang dibuat di Eropa. Pada dinding-dinding istana ada hiasan cat minyak motif floralistis dan geometris, ada yang distilir dan ada yang naturalistis. Pada plafonnya terdapat motif hiasan cat minyak motif floralistis dan geometris, ada yang distilir dan ada yang naturalistis yang diletakkan pada bidang-bidang segi empat dan segi delapan. Serta pada dinding ruangan ini juga tergantung figura dan lukisan serta foto-foto Sultan Deli para pendahulu yang memimpin Kesultanan Deli. Pada sudut bangunan atas terdapat bingkai cermin yang berwarna kuning emas itu terdapat hiasan floralistis yang distilir sedemikian rupa sehingga mengandung makna seperti bentuk makara. Pada bangunan istan ada figura cermin atau tingkap lunas perahu terbalik. Kombinasi tingkap-tingkap perahu terbalik dengan lubang-lubang ventilas ini yang ada pada bangunan istana maimun terdapat juga pada bangunan Masjid Raya, dimana bangunan masjid raya ini terletak didepan seberang jalan dari istana maimun. Pintu-pintu yang ada pada balairung mempunyai ukuran yang tinggi dan lebar seperti bangunan bergaya Eropa. Daun pintu bangunan istana terdiri dari dua lapis dimana yaitu ada bagian luar dan bagian dalam. Pada bagian luar daun pintunya terbuat dari kayu, sedangkan pada bagian dalam daun pintu terbuat dari kayu dan kaca. Di dalam ruangan ada terdapat beberapa perabotan set kursi buatan Eropa. Di sisi kanan bangunan dari di depan istana ada berdiri bangunan atau rumah Batak Karo, di mana di dalamnya ditempatkan sebuah meriam yang sudah puntung (putus). Istana Maimun didesain meniru berbagai gaya, yaitu gaya tradisional istana-istana Melayu yang memanjang di depan dan bertingkat dua, juga pola India Islam (Moghul) dan yang diambil dari Eropa. Begitu juga di dalam ukiranukiran, terutama di ruang Balairung Sri bercampur baur. Ukiran-ukiran Melayu tradisional dapat kita lihat pada "Pagar Tringgalum", pinggiran atas lesplank dengan bentuk "Pucuk Rebung" yang terkenal, dinding sebelah atasnya dengan bentuk "Awan Boyan", langit-langit dengan kubisme Adapun tahta singgasana baru didirikan di zaman pemerintahan Sultan Amaluddin Sani Perkasa Alamsyah, karena dan salah satu gambar lama masa Sultan Ma'mun Alrasyid memerintah, singgasananya berbentuk lain. Pada tahta yang ada sekarang, kita lihat ukiran foliage dan bunga corak ukiran Melayu yaitu "Bunga Tembakau", ukiran atas depan "Awan Boyan", samping atas bulatan bunga matahari. Berdasarkan prasasti berbahasa Belanda dan Melayu yang terdapat pada sekeping marmer di kedua tiang ujung tangga naik, peletakan batu pertama pembangunan Istana Maimun dilakukan pada tanggal 26 Agustus 1889 oleh Sultan Ma'mun Alrasyid Perkasa Alamsyah dan mulai ditempati pada tanggal 18 Mei 1891 jadi pengerjaan pembangunan istana maimun ini dilakukan selama 2 tahun lebih. Dengan demikian hingga pada saat ini usia bangunan istana maimun telah berusia satu abad, kurun waktu tersebut tidaklah terlalu tua ditinjau dari segi arkeologi. Akan tetapi pengertian tua atau kuno itu sendiri dari sudut kronologi relatif sifatnya, kalau dikaitkan dengan undang-undang kepurbakalaan yang masih berlaku di negeri kita yaitu monumenten ordonantie Stbl. No.238 tahun 1931, khususnya pasal 1 ayat 1 (a), jelas bahwa Istana Maimun ini termasuk bangunan purbakala atau monumen. Dengan kata lain, dari segi perundang-undangan (yuridis formal) perlu dan harus dilindungi, dipelihara dan dilestarikan karena telah berusia lebih dari 50 tahun agar dapat diwariskan kepada generasi penerus bangsa, termasuk di dalamnya upacara-upacara tradisional baik 
yang bernilai sakral maupun non sakral yang pernah dilaksanakan di masa lampau di Istana Maimun. Oleh karena itu bangunan istana maimun merupakan bangunan yang mempunyai nilai tradisi dan bagian dari budaya bangsa sebagai ciri khas kepribadian dan identitas bangsa yang mempertebal rasa harga diri dan kebanggaan nasional serta memperkokoh jiwa kesatuan nasional. Meskipun dari segi kronologis usia bangunan ini tidak begitu tua, namun dilihat dari sudut arsitektur dan sejarah kesenian sangat penting artinya karena mengandung nilai-nilai arsitektur yang tinggi. Pada bangunan ini terdapat juga unsur-unsur seni bangunan Indonesia dan unsur-unsur luar negeri seperti kebudayaan Persia, India dan Eropa. Perpaduan kebudayaan ini antara lain tercermin pada daerahnya, bentuk atap, ornamen atau ragam hias dan lain sebagainya. Walaupun bangunan ini mempunyai 3 bagian, yaitu bangunan induk dan kedua sayapnya dimuali dari denah dari setiap bagian itu mengingatkan pada ground plant bangunan-bangunan Islam seperti masjid-masjid, istana-istana di Timur Tengah atau India pada masa lampau terlihat seperti sama semuanya. Bagian tengah istana maimun yang bentuknya seperti segi empat dan biasanya digunakan sebagai ruangan terbuka pada masjid-masjid kuno di Timur Tengah maupun India disebut "shan" dan pada keempat sisi bangunan tersebut ada gambar atap tempat berteduh yang disebut "mughatha" atau "sutuh". Pada bagian-bagian yang ada pada Istana Maimun, baik pada bangunan induknya maupun kedua sayap telah ditutup dengan atap berbentuk limasan sehingga bangunan tersebut seperti ruangan-ruangan yang sangat luas dan lebar, sedangkan setiap gang yang ada atapnya yang mengitari setiap ruangan atau bagian jelas mengingatkan pada mugatha atau sutuh, walaupun konstruksi tiap bagian tidak sama karena pada sisi dalam gang beratap ini terdapat tembok atau dinding lengkap dengan pintu-pintu dan jendela-jendela yang terbuat kayu. Demikian juga dengan lengkungan-lengkungan atau arcade, baik yang berbentuk lunas perahu terbalik, atau lengkung runcing maupun lengkungan yang berbentuk ladam kuda atau lengkung asli pada gambar atap seperti mengingatkan dengan bentuk Liwin atau Liwanat yang terdapat dalam kesenian Islam Timur Tengah maupun India. Lengkungan-lengkungan atau arcade yang berbentuk lunas perahu terbalik atau lengkung runcing ini dalam kesenian Islam dikenal sebagai lengkungan yang berciri khas Persia, dan banyak juga digunakan di Turki, India dan Eropa. Dengan demikian bahwa bagian depan istana mengingatkan pada bentuk arcade bangunan-bangunan Islam bergaya Timur Tengah. Pada puncak atap terdapat hiasan bulan sabit yang menurut para ahli sering dihubungkan sebagai lambang kedamaian, di mana Islam disyiarkan tanpa kekerasan. Selain denah, atap kubah, lengkungan-lengkungan (arcade), hiasan bulan sabit pada puncaknya, pengaruh kesenian Islam ini akan lebih nampak lagi pada ornamentasinya, baik pada dinding, plafon, tiang-tiang dan permukaan lengkungan (face arcade) yang kaya dengan hiasan bunga-bungaan dan tumbuhtumbuhan yang berkelok-kelok dengan cat minyak. Hiasan floralistis selain digayakan (distiril) sehingga mengingatkan pada motif tumpal dan mekara, juga dilukis secara naturalistis. Kecuali motif flora, motif geometris juga amat menonjol adalah kombinasi antara hiasan polygonal (bersegi banyak), octagonal (bersegi delapan) dan lingkaran-lingkaran. Motif semacam ini terutama sekali terdapat pada dinding-dinding, permukaan lengkungan, plafond an sebagainya. Di samping itu, motif semacam ini terlihat pula pada bentuk terali besi, tingkap-tingkap (jendela) segi empat maupun yang berbentuk lengkungan yang mengingatkan kita pada ukiran dinding gaya India. Di Indonesia, bentuk hiasan seperti ini sering disebut dengan hiasan terawangan atau kerawangan, selain sebagai hiasan, hiasan tersebut juga berfungsi sebagai ventilasi atau lubang angina pada setiap bangunan. Kecuali pengaruh dari kesenian Islam Timur Tengah dan India, unsur luar yang menonjol pada Istana Maimun ini adalah pengaruh dari kesenian Eropa. Sebagian besar bahan bangunan atau material bangunan didapat dari luar negeri (diimpor) seperti traso, ubin marmer dan lain sebagainya, bahkan seluruh koleksi yang ada pada istana seperti kursi-kursi, meja, buffet, meja toilet dan sebagiannya adalah buatan dari Eropa. Meskipun unsur-unsur luar negeri pada bangunan istana maimun terlihat sangat amat menonjol, namun unsur-unsur seni atau ciri khas bangunan Indonesia pada Istana Maimun masih terlihat, misalnya terdapat pada atap limasan dengan konstruksi bertumpang atau 
bertingkat. Di samping itu pada penampil depan terdapat lesplank yang dipahat dengan hiasan pucuk rebung. Oleh karena itu, dilihat dari segi arsitekturnya, Istana Maimun memiliki nilai yang tinggi dan menduduki tempat tersendiri dalam sejarah kesenian Islam di Indonesia. Dan kalau Abu Bakar Aceh menyebutkan bahwa Masjid Raya Medan yang terletak di depan Istana Maimun sebagai satu-satunya masjid yang mewakili bentuk kesenian Islam di Indonesia. Apabila diperhatikan, Istana Maimun dapat dikatakan adalah merupakan satu-satunya bangunan istana yang dapat mewakili bentuk kesenian Islam di Indonesia pada umumnya dalam hubungannya dengan kesenian Islam Timur Tengah dan India. Di samping itu kalau dikaitkan dengan letak dan arah muka istana yang dihubungkan dengan Masjid Raya sebagai Masjid Istana (keraton) ternyata pola-pola keletakan istana (keraton) kuno dengan alun-alun sebagai titik sentralnya sesuai pada konteks Istana Maimun ini, sekalipun besar kemungkinannya bahwa areal antara bangunan istana dengan masjid raya dulu merupakan tanah lapangan atau alun-alun. Oleh karena itu, ditinjau dari sudut arkeologi maupun arsitekturnya, Istana Maimun termasuk salah satu di antara monumen yang harus dilindungi, dipelihara dan jika mungkin untuk dilestarikan agar generasi penerus tidak kehilangan data dalam merekonstruksikan masa lampaunya.

\section{KESIMPULAN}

Berdasarkan penelitian yang dilakukan dalam membuat analisis tentang langit-langit Istana Maiomoon ini maka ada beberapa simpulan yang didapat adalah :

1. Istana Maimun didominasi oleh warna kuning dimana warna tersebut adalah warna kebudayaan Melayu

2. Istana Maimun didirikan oleh Sultan Mahmoed Al Rasyid Perkasa Alamsyah pada tahun 1888

3. Arsitektur bangunan istana Maimun merupakan gabungan dari beberapa unsur budaya Eropa, Persia, Spanyol, India, Belanda dan Italia serta Timur Tengah.

\section{DAFTAR PUSTAKA}

[1] Buku Sejarah Singkat Istana Maimun

[2] Karina Juwita, Desain Plafon pada Auditorium Gedung Kesenian Jakarta, Jurnal Desain Interior, Vol. 2, No. 2 Desember 2017.

[3] Bradley, T. (1989). Practical Building Acoustics. Suffolk London: Sound ResearchLaboratories Ltd.

[4] Doelle, Leslie. L. dan Dra. Lea Prasetyo, M.Sc. (1972). Environtment Acoustic. New York: McGraw-Hill Book, Company.

[5] Doelle, Leslie. (1990). Akustik Lingkungan. Jakarta: Erlangga.

[6] Kuttruff, Heinrich. (1979). Room Acoustics. London: Spon Press 11 New Fetter Lane.

[7] Rettinger, M. (1970). Acoustics. New York: Chemical Publishing Company,Inc.

[8] Suptandar, J. Pamudji. (2004). Faktor Akustik Dalam Perancangan Desain Interior. Jakarta:Djambatan.

[9] Susanta, Gatut. (2008). Panduan Lengkap Membangun Rumah. Jakarta: PT. Gramedia Pustaka Utama. 
[10] http://bravaradio.com/10/12/menelusuri-kemegahan-istana-maimun-di-medan/

[11] https://travel.detik.com/domestic-destination/d-3189420/istana-maimun-di-medan-salah-satuyang-terindah-di-indonesia

[12] https://www.lpmdinamika.co/jalan-jalan/istana-maimun-destinasi-sejarah-kesultanan-delimasih-kokoh-berdiri/

[13] https://rudisony.wordpress.com/2010/09/05/istana-Maimun-medan/

[14] https://sportourism.id/explore/istana-maimun-istana-islam-dari-masa-kolonial

[15] https://belajarmemahamibersama.blogspot.com/2016/10/laporan-hasil-penelitian-padaistana.html

[16]https://tekno.kompas.com/read/2013/05/18/14095492/istana.Maimun.warisan.yang.tetap.bertah an

[17] https://syair4artikel.wordpress.com/sejarah-istana-maimun/

[18] https://www.innagroup.co.id/news/tempat-tujuan:-istana-maimun-saksi-bisu-kejayaankesultanan-deli

[19] https://www.republikaonline.comUIstana MaimunIIstana Maimun Nuansa Islam di Sumatra Utara _ Republika Online.html

[20] https://www.republikaonline.com Istana Maimun|Sentuhan Andalusia dan Persia di Istana Maimun _ Republika Online.html.

[21] https://id.wikipedia.org/wiki/Istana 